\title{
Expression of long noncoding RNA NBAT1 is associated with the outcome of patients with non- small cell lung cancer
}

\section{SUMMARY}

OBJECTIVE: Long noncoding RNA neuroblastoma-associated transcript 1 (NBAT1) has been reported to be involved in cancer progression. However, the clinical significance of NBAT1 in non-small cell lung cancer (NSCLC) is still unclear. Our present research aimed to explore whether NBAT1 serves as a biomarker for NSCLC prognosis.

METHODS: The expression of NBAT1 was examined by RT-PCR in tissue samples of 162 NSCLC patients and was compared with the adjacent non-tumor lung specimens. Then the association between NBAT1 expression and clinical-pathological parameters was further evaluated. Survival analysis was performed using the Kaplan-Meier method. The prognostic significance of NBAT1 expression in NSCLC patients was explored by the use of univariate and multivariate analyses.

RESULTS: NBAT1 expression was prominently decreased in NSCLC tissues compared with matched normal lung specimens ( $p<0.01$ ). Moreover, survival analyses indicated that patients with low expression displayed dramatically decreased 5-year overall survival ( $p=$ 0.008).

CONCLUSIONS: NBAT1 expression might contribute to tumor progression and poor prognosis of NSCLC and might be a new therapeutic target in NSCLC.

KEYWORDS: Prognosis. Carcinoma, non-small-cell lung. RNA long noncoding.

\section{INTRODUCTION}

Lung cancer has been the leading cause of cancer-associated deaths both in men and women around the world for the past decades, accounting for about $13 \%$ (1.8 million) of total cancer diagnoses in $2012^{1,2}$. Non-small cell lung cancer (NSCLC) accounts for $85 \%$ of all lung cancers ${ }^{3}$. CT perfusion can be used as an index for predicting mediastinal lymph node metastasis of lung cancer ${ }^{4}$. In China, the total number of deaths annually is around half a million. Therefore, NSCLC has posed a serious threat to public health ${ }^{5}$.

Long noncoding RNAs (lncRNAs) have been identified as a subclass of ncRNAs with a length of $>200$ 
nucleotides that are unlikely to be translated into proteins due to a lack of an open-reading frame ${ }^{6,7}$. Growing evidence has demonstrated that lncRNAs are involved in transcriptional, translational, and epigenetic regulation ${ }^{8}$. It has been identified that IncRNAs play a crucial role in several cellular processes, including cell development, growth, differentiation, invasion, and apoptosis ${ }^{9,10}$. The newly identified IncRNAs display specimen-specific expression patterns. Recently, growing studies report that IncRNAs play indispensable roles in several biological progressions involved in the pathogenesis of various cancers, such as proliferation and apoptosis in cervical cancer, liver cancer, NSCLC and so on, by functioning as oncogenes, tumor suppressor genes or both, depending on the conditions ${ }^{11-13}$. The frequent dysregulation of critical lncRNAs and their important biological function in tumors highlighted the clinical application of lncRNAs as a novel clinical tool for the diagnosis and prognosis of NSCLC patients ${ }^{14,15}$. Although more and more lncRNAs have been identified to have the capability to serve as a novel biomarker, due to the tremendous amount of IncRNAs, many remain to be elucidated.

LncRNA neuroblastoma associated transcript 1 (NBAT1), also known as CASC14, was located at 6 p22.3 and was initially identified to be dysregulated in neuroblastoma ${ }^{16}$. Then, several studies reported that NBAT1 expression was down-regulated in several tumors, such as bladder cancer, glioblastoma, osteosarcoma ${ }^{17-19}$. In addition, both in vitro and in vivo assays confirmed the tumor-suppressive roles of NBAT1 in the above tumors. Of note, a recent study by Zheng et al. ${ }^{20}$ firstly reported that NBAT1 may be lowly expressed in NSCLC cells, and its overexpression could inhibit tumor progress by inhibiting autophagy in NSCLC. However, the clinical significance of NBAT1 in NSCLC remained to be further demonstrated.

In this study, we provide the first clinical evidence that NBAT1 may act as a potential prognostic biomarker for NSCLC patients.

\section{METHODS}

\section{Patients and Specimens}

NSCLC tissues and normal specimens of the lung were obtained from patients who had undergone surgery at the First People's Hospital of Jinan, between 2010 and 2013. All patients included in our clinical assays were diagnosed with NSCLC by two pathologists based on histopathological evaluation. All the above specimens were flash-frozen in liquid nitrogen immediately after resection and stored at $-80^{\circ} \mathrm{C}$ for further RT-PCR experiments. Patients who experienced any of the following conditions were excluded: recurrent NSCLC; undergoing immune inhibitive treatments; with other serious diseases. Clinical information of all NSCLC patients was available. The overall survival was defined as the time from surgery to death. The clinicopathological features of all patients are presented in Table I. Informed consent was obtained from each patient, and all of the experiments were approved by the ethics committee of the institute.

\section{RNA preparation and quantitative RT-PCR}

Total RNA was extracted from tumor specimens and matched non-neoplasm specimens using Trizol

TABLE1. CORRELATION BETWEEN THE EXPRESSION OF NBAT1 AND CLINICOPATHOLOGICAL

\begin{tabular}{|c|c|c|c|c|}
\hline \multirow{2}{*}{$\begin{array}{l}\text { Clinicopathological } \\
\text { parameters }\end{array}$} & \multirow{2}{*}{$\begin{array}{l}\mathrm{N} \text { of } \\
\text { cases }\end{array}$} & \multicolumn{2}{|c|}{ NBAT1 expression } & \multirow[t]{2}{*}{$\mathrm{p}$-value } \\
\hline & & High & Low & \\
\hline Age(years) & & & & NS \\
\hline$\geq 65$ & 87 & 46 & 41 & \\
\hline$<65$ & 75 & 34 & 41 & \\
\hline Gender & & & & NS \\
\hline Male & 104 & 50 & 54 & \\
\hline Female & 58 & 30 & 28 & \\
\hline Differentiation & & & & NS \\
\hline Well, moderate & 58 & 33 & 25 & \\
\hline Poor & 104 & 47 & 57 & \\
\hline Tumor size & & & & NS \\
\hline$\geq 4 \mathrm{~cm}$ & 49 & 29 & 20 & \\
\hline$<4 \mathrm{~cm}$ & 113 & 51 & 62 & \\
\hline Primary location & & & & NS \\
\hline Left lung & 76 & 41 & 35 & \\
\hline Right lung & 86 & 39 & 47 & \\
\hline Histology type & & & & NS \\
\hline Adenocarcinoma & 114 & 58 & 56 & \\
\hline Squamous carcinoma & 48 & 22 & 26 & \\
\hline Smoking history & & & & NS \\
\hline Smokers & 81 & 43 & 38 & \\
\hline Never smoked & 81 & 37 & 44 & \\
\hline Lymph node metastasis & & & & 0.010 \\
\hline Positive & 52 & 18 & 34 & \\
\hline Negative & 110 & 62 & 58 & \\
\hline TMN stage & & & & 0.005 \\
\hline 1 & 60 & 21 & 39 & \\
\hline$\| / I I$ & 102 & 59 & 43 & \\
\hline
\end{tabular}

features of NSCLC patients ( $n=162)$. 
reagent (Life Technologies Corporation, Zhejiang, Hangzhou, China). First-strand cDNA was generated using the Reverse EasyScript One-Step gDNA Removal and cDNA Synthesis SuperMix (TaKaRa, Dalian, Liaoning, China). NBAT1 expressions were assessed applying RT-PCR with SYBR Premixe Ex Taq (TaKaRa, Dalian, Liaoning, China) and 7500 real-time PCR system (Applied Biosystems, Kunming, Yunan, China). The sequences of the primers were as follows: NBAT1: forward ACTGAAACCCACAGAGATGAAG, NBAT1: reverse CCCGTCATGTAGAGCAATATCC, GAPDH: forward GGAGCGAGATCCCTCCAAAAT, GAPDH: reverse GGCTGTTGTCATACTTCTCATGG. Real-time RTPCR reactions were performed by the ABI7500 system (Applied Biosystems, Kunming,
Yunan, China). All experiments for NBAT1 examination were performed in triplicate. Glyceraldehyde-3-phosphate dehydrogenase (GAPDH) was used as an internal control. The relative expressing levels of NBAT1 was calculated by the use of the $2^{\Delta \Delta \mathrm{Ct}}$ methods.

\section{Statistical analysis}

The statistical analysis was performed using SPSS 16.0 software (SPSS Inc., Chicago, IL, USA). The NBAT1 expression levels in NSCLC were compared with those in adjacent non-tumor specimens with the use of the Wilcoxon test. A $\chi^{2}$ test or Fisher's exact test was applied to determine the association between NBAT1 level and clinical characteristics.

TABLE 2. UNIVARIATE AND MULTIVARIATE ANALYSES FOR OVERALL SURVIVAL BY COX REGRESSION MODEL.

\begin{tabular}{l|l|l|l|l|l|l}
\multirow{2}{*}{ Parameters } & \multicolumn{5}{l}{ Univariate analysis } & \multicolumn{3}{l}{ Multivariate analysis } \\
\cline { 2 - 8 } & HR & $95 \% \mathrm{Cl}$ & $\mathrm{P}$ & $\mathrm{HR}$ & $95 \% \mathrm{Cl}$ & $\mathrm{P}$ \\
\hline Age & 1.642 & $0.447-2.514$ & 0.445 & - & - & - \\
\hline Gender & 1.437 & $0.764-2.321$ & 0.231 & - & - & - \\
\hline Differentiation & 1.854 & $0.652-2.554$ & 0.164 & - & - & - \\
\hline Tumor size & 2.213 & $0.894-2.664$ & 0.108 & - & - & - \\
\hline Primary location & 1.885 & $0.752-2.441$ & 0.113 & - & - & - \\
\hline Histology type & 1.543 & $0.654-2.231$ & 0.156 & - & - & - \\
\hline Smoking history & 1.364 & $1.047-1.986$ & 0.136 & - & - & - \\
\hline Lymph node metastasis & 3.465 & $1.447-5.764$ & 0.004 & 3.174 & $1.194-4.776$ & 0.011 \\
\hline TMN stage & 3.572 & $1.539-5.127$ & 0.007 & 3.048 & $1.238-4.476$ & 0.015 \\
\hline NBAT1 expression & 3.374 & $1.429-4.775$ & 0.009 & 2.947 & $1.184-4.369$ & 0.014 \\
\hline
\end{tabular}

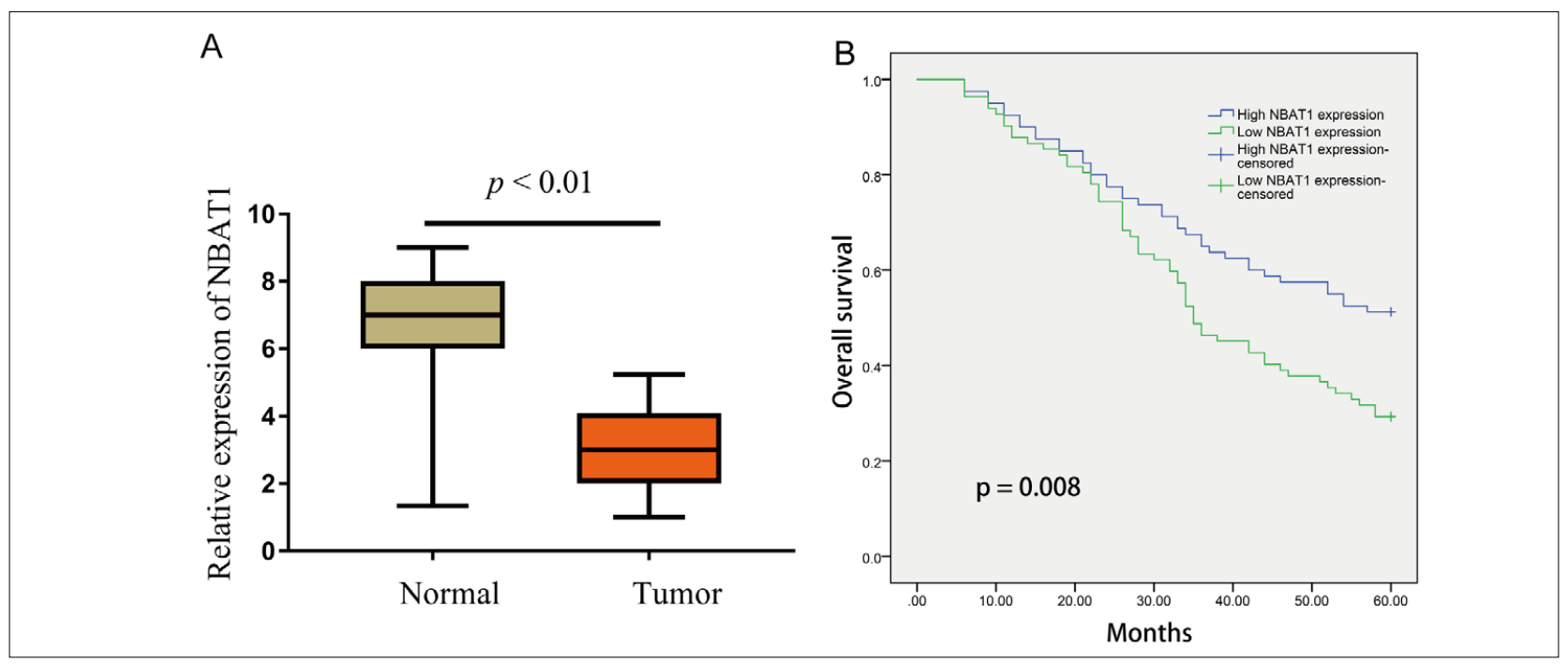

FIGURE 1. NBAT1 OVEREXPRESSION PREDICTS A POOR PROGNOSIS IN NSCLC PATIENTS.

(A) Expression levels of NBAT1 in NSCLC and adjacent non-cancerous tissues. The expression level of NBAT1 was significantly higher in NSCLC tissues than in adjacent noncancerous tissues $(p<0.01)$. (B) The association between patient survival and NBAT1 expression was estimated using the Kaplan-Meier method and the log-rank test $(p=0.008)$. 
Survival curves were constructed with the KaplanMeier method and compared by the log-rank test. For further identifying the potential independent prognostic factors, the Cox proportional hazard regression model was performed. A $p$-value of less than 0.05 was considered significant.

\section{RESULTS}

Reduced expression of NBAT1 is confirmed in NSCLC

To explore whether NBAT1 could be a functional factor in NSCLC, our group secured 162 pairs of NSCLC specimens and matched non-neoplasm tissues and carried out qRT-PCR. As shown in Figure1A, quantitative data revealed that the levels of NBAT1 in NSCLC tissues were prominently lower than those in matched non-neoplasm specimens $(p<0.01)$. Our results were consistent with a previous study by Zheng et al. ${ }^{20}$.

Association of NBAT1 expression with clinicopathological characteristics of NSCLC patients

To further understand whether the down-regulation of NBAT1 may influence the clinical progress of NSCLC patients, we divided the 162 NSCLC patients into a high expression group $(\mathrm{n}=80)$ and a low expression group $(n=82)$ using the mean level of NBAT1 as a reference. The association between clinicopathological characteristics and NBAT1 expression is shown in Table1. The results of the chi-square test showed that a low NBAT1 level was also significantly associated with lymph node metastasis $(p=0.010)$ and advanced TMN stage $(p=0.005)$. However, no distinct difference was discovered between NBAT1 expression and patient age, gender, differentiation, tumor size, primary location, histology type, and smoking history $(p>0.05)$.

\section{Prognostic values of NBAT1 levels in NSCLC}

Then, we further explored whether NBAT1 expression was associated with the clinical outcome of NSCLC patients, and a follow-up of NSCLC patients was conducted over a 5-year period, in which the overall survival rates of patients were recorded. Furthermore, the Kaplan-Meier method and log-rank test revealed that patients with high NBAT1 expression in NSCLC had prominently longer overall survival than those with low NBAT1 expression $(p=0.008$, Figure
1B). Then, the univariate analysis demonstrated that lymph node metastasis, TMN stage, and NBAT1 expression were statistically significant risk factors affecting the overall survival of NSCLC patients $(p<0.05$, Table 2). Of note, multivariate analysis showed that NBAT1 expression was an independent prognostic factor for NSCLC patients (HR= 2.947, 95\% CI: 1.184-4.369, $p=$ 0.014, Table 2). Overall, our results suggested NBAT1 is a potential prognostic regulator for NSCLC patients.

\section{DISCUSSION}

In this study, firstly, we collected tumor specimens and performed RT-PCR to further study the expression of NBAT1 in NSCLC, finding that NBAT1 expression levels were prominently lower in NSCLC tissues. Our results were consistent with previous results. Then, we further proved that low levels of NBAT1 were prominently associated with positive lymph node metastasis and advanced TMN stage, suggesting that NBAT1 may act as a positive regulator to contribute to the clinical progress of NSCLC. Subsequently, we further performed Kaplan-Meier assays to explore whether dysregulation of NBAT1 was associated with the prognosis of NSCLC patients, finding that patients with low levels of NBAT1 had poorer survival time than those with high levels of NBAT1. More importantly, based on the data of univariate and multivariate assays, low expression of NBAT1 was demonstrated to be a poor independent prognostic factor for patients with NSCLC, and the HR (95\% CI) was 2.947 (1.184-4.369).

NSCLC contributes prominently to tumor-associated mortality and has become a major public health burden in China. Despite the rapid progress in NSCLC research, the survival of patients remains poor $^{21}$. Lack of adequate cancer markers for early screening and metastasis determination further compromises the early diagnosis and treatment of this disease ${ }^{22}$. In addition, the precise prediction of clinical outcomes for NSCLC patients is very important for doctors to design individualized therapy ${ }^{23}$. Although several clinic-pathological factors have been used for the clinical application in prediction of prognosis of NSCLC patients, the specificity and sensibility of these factors remain low ${ }^{24}$. The clinical progress of NSCLC is involved in the dysregulation of multiple genes.

In their in vitro and in vivo assays, it was confirmed that forced expression of NBAT1 suppresses 
the metastasis of breast cancer cells by modulating the DKK1/PRC2 axis. Yang et al. ${ }^{19}$ showed that NBAT1 was lowly expressed in osteosarcoma and its overexpression growth, migration, and invasion of osteosarcoma cells via sponging miR-21. Liu et al. ${ }^{17}$ indicated that the up-regulation of NBAT1 suppressed the migration and invasion of bladder cancer cells through the miRNA21/SOCS6 axis. These findings suggested NBAT1 as an oncogene in the above tumors. Recently, Zheng et al. ${ }^{20}$ firstly reported that NBAT1 expression was down-regulated in NSCLC cell lines, and its overexpression exhibited a tumor-suppressive role by suppressing autophagy by modulating ATG7. However, the expression pattern of NBAT1 needed to be further confirmed. In addition, the clinical significance of NBAT1 in NSCLC patients has not been investigated.

\section{CONCLUSIONS}

This is the first study highlighting the clinical significance of NBAT1 in NSCLC. Lower NBAT1 expression could serve as a promising target or potential prognostic indicator for NSCLC. More in-depth and larger-scale studies are required to confirm the correlation described here.

\section{Conflict of Interest}

No conflicts of interest.

\section{Author's Contribution}

All authors contributed to data analysis, drafting and revising of the article, gave final approval of the version to be published, and agree to be accountable for all aspects of the work.

\section{RESUMO}

OBJETIVO: Há relatos de que o NBAT1 está associado à progressão do câncer. Contudo, o significado clínico do NBAT1 no câncer de pulmão de células não pequenas (NSCLC) ainda não está claro. O objetivo da nossa pesquisa foi explorar se NBAT1 serve como biomarcador para o prognóstico de NSCLC.

MÉTODOS: A expressão de NBAT1 foi examinada por RT-PCR em amostras de tecido de 162 pacientes com NSCLC e comparada a amostras adjacentes não tumorais de pulmão. Em seguida, a associação entre a expressão do NBAT1 e os parâmetros clínico-patológicos foi avaliada. A análise de sobrevivência foi realizada utilizando o método Kaplan-Meier. A significância prognóstica da expressão do NBAT1 em pacientes com NSCLC foi explorada através de análises univariadas e multivariadas.

RESULTADOS: A expressão do NBAT1 foi claramente diminuída nos tecidos de NSCLC em comparação aos espécimes normais dos pulmões $(p<0,01)$. Além disso, as análises de sobrevivência indicaram que pacientes com baixa expressão apresentavam uma diminuição drástica da sobrevivência global em cinco anos $(p=0,008)$.

CONCLUSÃO: A expressão do NBAT1 pode contribuir para a progressão tumoral e um prognóstico negativo do NSCLC e pode ser um novo alvo de terapia no NSCLC.

PALAVRAS-CHAVE: Prognóstico. Carcinoma pulmonar de células não pequenas. RNA longo não codificante.

\section{REFERENCES}

1. Torre LA, Siegel RL, Jemal A. Lung cancer statistics. Adv Exp Med Biol. 2016;893:1-19.

2. Siegel RL, Miller KD, Jemal A. Cancer statistics, 2016. CA Cancer J Clin 2016;66(1):7-30

3. Xu FX, Zhang YL, Liu J), Zhang DD, Chen HB. Hypoxic markers in nonsmall cell lung cancer (NSCLC): a review. Eur Rev Med Pharmacol Sci. 2016;20(5):849-52

4. Yang L, Sun L, Liu J, Liu Q. Role of low dose 256-slice CT perfusion imaging in predicting mediastinal lymph node metastasis of lung cancer. Rev Assoc Med Bras. 2019;65(6):761-6.

5. Chen W, Zheng R, Baade PD, Zhang S, Zeng H, Bray F, et al. Cancer statistics in China, 2015. CA Cancer J Clin. 2016;66(2):115-32.

6. Jandura A, Krause HM. The new RNA World: growing evidence for long noncoding RNA functionality. Trends Genet. 2017;33(10):665-76.

7. Deniz E, Erman B. Long noncoding RNA (lincRNA), a new paradigm in gene expression control. Funct Integr Genomics. 2017;17(2-3):135-43.
8. Mercer TR, Dinger ME, Mattick JS. Long non-coding RNAs: insights into functions. Nat Rev Genet. 2009;10(3):155-9.

9. Chen LL. Linking long noncoding RNA localization and function. Trends Biochem Sci. 2016;41(9):761-72.

10. Xiong $G$, liang $X$, Song T. The overexpression of IncRNA H19 as a diagnostic marker for coronary artery disease. Rev Assoc Med Bras. 2019;65(2):110-7.

11. Hu YC, Wang AM, Lu JK, Cen R, Liu LL. Long noncoding RNA HOXD-AS1 regulates proliferation of cervical cancer cells by activating Ras/ERK signaling pathway. Eur Rev Med Pharmacol Sci. 2017;21(22):5049-55.

12. Wang Y, Chen F, Zhao M, Yang Z, Li J, Zhang S, et al. The long noncoding RNA HULC promotes liver cancer by increasing the expression of the HMGA2 oncogene via sequestration of the microRNA-186. J Biol Chem. 2017;292(37):15395-407.

13. Wang D, Gao ZM, Han LG, Xu F, Liu K, Shen Y. Long noncoding RNA CASC2 inhibits metastasis and epithelial to mesenchymal transition of lung adenocarcinoma via suppressing SOX4. Eur Rev Med Pharmacol Sci. 2017;21(20):4584-90. 
14. Deng H, Wang |M, Li M, Tang R, Tang K, Su Y, et al. Long non-coding RNAs: new biomarkers for prognosis and diagnosis of colon cancer. Tumour Biol. 2017;39(6):1010428317706332.

15. Chen J, Wang R, Zhang K, Chen LB. Long non-coding RNAs in non-small cell lung cancer as biomarkers and therapeutic targets. J Cell Mol Med. 2014;18(12):2425-36.

16. Pandey GK, Mitra S, Subhash S, Hertwig F, Kanduri M, Mishra K, et al. The risk-associated long noncoding RNA NBAT-1 controls neuroblastoma progression by regulating cell proliferation and neuronal differentiation. Cancer Cell. 2014;26(5):722-37.

17. Liu Z, Xie D, Zhang H. Long noncoding RNA neuroblastoma-associated transcript 1 gene inhibits malignant cellular phenotypes of bladder cancer through miR-21/SOCS6 axis. Cell Death Dis. 2018;9(10):1042.

18. Liu J, Wang WM, Zhang XL, Du QH, Li HG, Zhang Y. Effect of downregulated IncRNA NBAT1 on the biological behavior of glioblastoma cells. Eur Rev Med Pharmacol Sci. 2018;22(9):2715-22.
19. Yang C, Wang G, Yang J, Wang L. Long noncoding RNA NBAT1 negatively modulates growth and metastasis of osteosarcoma cells through suppression of miR-21. Am J Cancer Res. 2017;7(10):2009-19.

20. Zheng T, Li D, He Z, Feng S, Zhao S. Long noncoding RNA NBAT1 inhibits autophagy via suppression of ATG7 in non-small cell lung cancer. Am J Cancer Res. 2018;8(9):1801-11.

21. Hensing T, Chawla A, Batra R, Salgia R. A personalized treatment for lung cancer: molecular pathways, targeted therapies, and genomic characterization. Adv Exp Med Biol. 2014;799:85-117.

22. Vargas AJ, Harris CC. Biomarker development in the precision medicine era: lung cancer as a case study. Nat Rev Cancer. 2016;16(8):525-37.

23. Li B, Cui Y, Diehn M, Li R. Development and validation of an individualized immune prognostic signature in early-stage nonsquamous non-small cell lung cancer. JAMA Oncol. 2017;3(11):1529-37.

24. de Groot P, Munden RF. Lung cancer epidemiology, risk factors, and prevention. Radiol Clin North Am. 2012;50(5):863-76. 